\title{
Understanding Teacher Beliefs and Instructional Decision Making Concerning Disciplinary Literacy: The Case of Secondary Teachers in an Urban School
}

\author{
Kellee D. Jenkins \\ Howard University \\ Washington, D.C., USA
}

\begin{abstract}
This study was set to examine the integration of disciplinary literacy instruction as part of a comprehensive literacy program at the secondary level. The study asked two essential questions: (1) What are teachers' knowledge and beliefs about disciplinary literacy instruction? (2) How do teachers' knowledge and beliefs influence their instructional decision making? Eight teachers were interviewed and observed. Results indicate that teachers believe they are responsible for developing students' literacy skills in the discipline they taught. Teachers emphasize discipline specific literacy practices and strategies to improve students' literacy skills as well as to enhance students' content knowledge. Findings also specify that professional development is a key factor in the continuity and success of teachers' literacy instruction across the disciplines. Through professional development, teachers appear to develop a deep understanding of what it means to engage students in discipline specific literacy practices.
\end{abstract}

Keywords: Teacher beliefs; Disciplinary literacy instruction; Teacher preparation; Professional development.

\section{Introduction}

Discipline specific literacy instruction focuses on teaching students how literacy is used appropriately in different disciplines. As such, subject area teachers must view literacy instruction through the lens of their discipline and use instructional literacy strategies that will increase the habits of mind in their respective discipline. In short, science teachers should teach students to read and think like scientists and math teachers should teach students to read and think like mathematicians. Each discipline requires specialized literacies that are the most pertinent to the content they are learning. Discipline specific literacy emphasizes those literacy practices that are used to read, write, think and communicate within each discipline (Moje, 2008; Shanahan \& Shanahan, 2012). 
This shifting paradigm requires secondary subject teachers to infuse disciplinary literacy instruction while simultaneously teaching subject-matter content. This shift also calls for eliminating the use of one-size, which fits all reading strategies and emphasizing the literacy strategies that support discipline learning. The transition from content area literacy to discipline specific literacy instruction also requires a transformation in the structure of secondary schools. Although discipline specific literacy instruction offers promising results for adolescent learners, schools must contend with developing a framework that not only supports students' to increase their literacy skills for college and career readiness, but also to develop teachers' ability to address the increasing number of students who make up academically diverse secondary classrooms. Thus, the challenge of discipline specific literacy instruction requires school wide with reforms to school culture and context as well as to teacher learning and professional development.

\section{Theoretical Framework}

This study is anchored in a disciplinary learning perspective. From a disciplinary literacy stance, learning in the disciplines involves instruction that embeds advanced literacy practices that are critical in building and understanding specific content area knowledge (Moje, 2008; Shanahan \& Shanahan, 2012; Goldman et al., 2016). Content area teachers, therefore, become responsible for engaging students in content information while integrating sophisticated literacy practices that characterize their disciplines. If students are to develop an array of advanced literacy skills that are specific to each discipline, then teachers must possess the necessary content knowledge of the subject they teach, and they must understand the importance of promoting discipline specific literacy practices in order for students to gain deep understanding of content specific information.

Disciplinary literacy learning evolves as subject matter becomes more differentiated and complex and moves from using reading, writing, and speaking to learning content knowledge to incorporating higher order thinking skills such as investigating, conceptualizing, reasoning, and inferring (McConachie, 2010; Heller \& Greenleaf, 2007). Since disciplinary learning involves students in developing content knowledge by using advanced literacy skills, teachers must provide students with ongoing support so that students are capable of accessing knowledge in discipline specific classes. This type of learning requires students to engage in a range of higher order thinking skills that will allow for varied and thorough understanding that is associated with learning complex knowledge for each discipline.

Students continually develop critical literacy skills to gain and access disciplinary knowledge. This view of literacy conveys that content and literacy instruction are inextricably intertwined and are equally important. Disciplinary learning emphasizes the notion that content understanding is promoted through literacy understanding and literacy is used to support and enhance content learning (McConachie, 2010; Moje, 2008). Disciplinary learning involves teaching 
students how the disciplines are different from one another and how to develop the critical literacy skills that are necessary to understand how knowledge is produced and obtained in each discipline (Moje, 2008; Bain, 2000). Through disciplinary learning, each discipline functions as its own unique domain that specifies the ways in which literacy is used to access and learn information in a particular discipline. Students develop specialized knowledge by gaining an understanding of the ways of thinking and knowing within a discipline. As a result, students become part of different discipline specific communities who are able to think and act as if they were historian, mathematicians, and scientists.

As junior members of a particular discipline, students are able to use distinct bodies of knowledge specific to that discipline to learn content knowledge more deeply and to develop discipline specific literacy skills. Disciplinary literacy allows students to learn the core concepts and ideas of a particular discipline. Thus, disciplinary learning involves a process in which students learn how to read, reason, write, inquire, speak, and to construct knowledge within various discipline specific communities.

The disciplinary learning perspective also supports the intentionality and commonality of purpose in preparing teachers and schools to integrate and sustain disciplinary literacy instruction (Conley, 2008). Therefore, teachers' decision-making and instructional practices are influenced by the structure of the school's organization. Integrating literacy practices into content area classes is highly dependent upon the coherence of multiple, complex and interactive components of a school's structure and organization (Knapp, Copland, \& Talbert, 2003). By way of illustration, meeting the literacy needs of adolescent learners is complex. The goal of developing proficient readers requires an organizational approach in which school leaders create structures that allow teachers to acquire the necessary knowledge about discipline specific literacy instruction that reinforces important literacy skills while teaching discipline specific concepts (Goldman et al., 2016; Biancarosa \& Snow, 2006; Heller \& Greenleaf, 2007). An effective, comprehensive, and coordinated literacy program at the secondary level is only obtainable when student learning, professional learning, and system learning are addressed (Knapp, Copland, \& Talbert, 2003). The basis for disciplinary learning stems from the need to prepare students for challenging tasks, both in school and beyond, that would require them to read and write about complex subject matter material and to communicate their contextualized thinking in varied forms (McConachie et al., 2010). For this type of disciplinary learning to take root, secondary schools have to create integrated and coherent framework that articulate how successful students think and learn and define the level of literacy instruction and skill development students need for continued academic growth and preparedness for college and the workforce (Conley, 2008).

\section{Review of Literature}

For more than a century, research has supported the benefits students receive from literacy instruction in content area classes (Hall, 2005; Moore, Readence, \& Rickelman, 1983; Herber, 1970). The integration of literacy instruction into 
content area classes has remained a salient topic in research literature, teacher preparation programs, and school reform efforts. Addressing students' literacy needs at the secondary level have traditionally revolved around content area teachers who promote literacy through the infusion of generic reading strategies within their content instruction and supplemental interventions for struggling readers. Despite continued efforts to meet the needs of adolescents by encouraging teachers to incorporate literacy instruction into their classes, discipline specific literacy instruction has been difficult to infuse at the secondary level and has done little to significantly enhance the reading achievement of adolescent learners.

Students entering high school must possess a range of reading abilities that allow them to navigate through various content area texts for different purposes. Thus, content area literacy has shifted from the use of general reading strategies to a more discipline specific approach to learning in which students engage in sophisticated and specialized literacy practices particular to the various subjects (Moje, 2008; Shanahan \& Shanahan, 2012; Castek \& Beach, 2013). This type of disciplinary learning approach to literacy instruction not only emphasizes students' ability to construct meaning from multiple texts in multiple forms of print, but also promotes content knowledge and critical literacy skills unique to each academic discipline. Discipline specific literacy instruction at the secondary level involves a complex process that entails changes at the instruction, leadership, and organization levels. Thus, teacher beliefs and knowledge of literacy instruction, the lack of effective professional development, teacher collaboration across disciplines, and organizational constraints are the most influential factors that challenge a school's ability to integrate discipline specific literacy instruction.

\section{Teacher Beliefs and Literacy Knowledge}

Bransfords et al. (2000) state that expert teachers know the structure of the knowledge in their disciplines, which provides them with the cognitive roadmaps that guide their instructional decisions. Content area teachers can anticipate when students may struggle with grasping difficult information or where they may encounter conceptual barriers that hinder their learning. Similarly, teachers use pedagogical knowledge in conjunction with content knowledge to make decisions about instructional practices and to create effective learning environments (Bransford et al, 2000; Shulman, 1987). Despite the type or amount of knowledge content area teachers may have, their instructional decisions largely influenced by their beliefs (Buchman, 1997). However, teacher beliefs and knowledge are closely related. Teachers typically have knowledge about the subject they teach, but they may also have a range of beliefs about what and how students should learn (O'Brien, Stewart, \& Moje, 1995; Shulman, 1987). Teacher knowledge can influence teachers' beliefs in that they use their knowledge about content or teaching methods to guide their belief about how they teach and what students should learn. Hence, teachers' beliefs can also shape their knowledge. Pajares (1992) suggests that when confronted with new 
knowledge, teachers process and interpret that knowledge and decide whether that knowledge aligns with their beliefs or not. Regardless of whether or not their beliefs are correct, teachers tend to hold to their beliefs when presented with new or more accurate knowledge.

Teachers' beliefs are not only situated within their knowledge of a specific subject, but also within their instructional practices. The structure of secondary classrooms has historically revolved around a classroom culture defined by the teacher's beliefs about the following: the nature of knowledge, learning and instruction within a specific academic discipline, and past school experiences (Moje 2015; Moje, 1996). Depending on the teacher's beliefs, discipline specific literacy instruction may or may not be a relevant component in secondary classrooms. Moore, Readence, \& Rickelman (1983) note that subject matter specialists tend to emphasize content rather than students' acquisition of information. Although some teachers choose to incorporate content area literacy instruction, the majority of teachers believe that reading is not a necessity for success in content area classes and that they are neither qualified nor responsible for literacy instruction (Heller \& Green Leaf, 2007; Hall, 2005). Hall (2005) found that content area teachers held common beliefs such as they are not qualified to teach reading; they are responsible of reading instruction in their discipline; and that specific reading strategies are not a necessity in order for students to be successful in their class.

To combat such enduring beliefs, teacher preparation programs began requiring a content area-reading course to assist the future endeavors of pre-service teachers' reading instruction in their discipline specific classes (Hall, 2005, Herber, 1970). Although research conveys that teacher education courses can encourage pre-service teachers in developing positive attitudes and beliefs towards discipline specific literacy instruction, it also suggests teachers' knowledge about literacy instruction in the disciplines which may not transfer into their instructional practices upon entering the classroom (Hall, 2005; Bean, 2000). Donahue (2000) argues that a content area reading course can influence teachers' beliefs toward discipline specific reading instruction. He suggests that teachers need to be encouraged to examine their knowledge about and experiences to better understand the role of discipline specific literacy instruction. By engaging in more experiences with reading through professional learning opportunities, teachers can embrace the act of reading and be to develop methods that would help students become better readers based on their own professional learning experiences.

To further deepen understanding of their knowledge about themselves as learners, content area teachers should have continuous professional development opportunities themselves to interact with texts as readers so that they begin to develop attitudes and perceptions that view reading as a valuable and meaningful process within the content areas (Bintz, 1997). Regardless of the approach used to increase teacher knowledge about discipline specific literacy instruction, middle and high school teachers express difficulties in incorporating literacy instruction, and they continue to use their beliefs to guide their 
instructional practices and decisions about teaching, learning, and literacy in discipline specific classes (Anders, Hoffman, \& Duffy, 2000; Hall, 2005).

\section{Teacher Learning and Professional Development}

Research suggests that teachers' attitudes and beliefs about literacy instruction in the disciplines can be changed when teachers are given the opportunity to learn how to incorporate discipline specific literacy instruction (Torgesen et al., 2007; Biancarosa \& Snow, 2006; NRP, 2000). In order for teachers to transform their thinking and learn how to integrate literacy instruction in their discipline, schools must develop an infrastructure that allows teachers to engage in professional learning opportunities that aid them in developing and incorporating effective literacy practices. Professional development opportunities are ultimately designed to improve student learning and academic achievement by enhancing teachers' attitudes, knowledge, and instructional skills (Guskey, 2000). Within a school wide literacy reform at the secondary level, such professional development evolves from extended opportunities to learn over a period amount of time. Anders, Hoffman and Duffy (2000) suggest that effective professional development involves an extensive commitment to involving teachers in opportunities to learn through ongoing support, deliberation, and collaboration. While teachers need to participate in activities that allow them to critically reflect on their instructional practices, they also need time to develop the necessary subject matter knowledge. Desimone et al. (2002) emphasize that the focus of school based professional development should primarily revolve around the content that teachers teach and should align with their actual work in the classroom so that teachers develop deep content and pedagogical knowledge as well as understand how students learn the content.

Research has widely supported the notion that professional development must expose teachers to sustained, ongoing job-embedded professional learning opportunities that are supported by effective modeling and coaching that specifically address the needs of the teachers and the school (Bean, 2004; Anders et al., 2000; Guskey, 2000; Darling-Hammond \& McLaughin, 1994). Shanahan and Shanahan (2012) also note that secondary content teachers display a range of different instructional approaches that vary in how each discipline addresses content knowledge and literacy instruction and learning. Content area teachers may possess an awareness of how they use reading and texts to convey and evaluate content knowledge; however, the teachers struggled to understand how the use of discipline specific literacy strategies enhanced content learning. Therefore, teachers need professional learning opportunities specific to the discipline they teach since they engage their students in unique literacy practices depending on the content being studied.

\section{Context of Study}

The context of this study played an important role in understanding what beliefs secondary teachers held regarding disciplinary literacy and how their beliefs influenced their instructional decision making. The setting and participants 
provided specific cultural and historical information situated in a particular place and time (Graue \& Walsh, 1998).

\section{Setting}

The Study was conducted at a large urban high school in Northeast America. The majority of students are students of color who represent diverse, multicultural backgrounds. The student population was representative of thirty different countries and seventeen world languages. Of the 4,787 students, $69 \%$ are Latinos, 15\% are African Americans, 16\% are Caucasians, 1\% are Asian, and $1 \%$ were classified as other. To meet the various academic and social needs of its multicultural population, the school has seventeen academic departments and offers over five hundred course offerings ranging from college preparatory to vocational technology.

One of the school's major goals was to ensure that all students are academically and socially prepared to graduate from high school and enter college or the high skilled workforce. As a result, the school offers more than forty support programs and school activities to ensure students' academic and social success. The school as a whole has struggled to meet the state's requirements for annual yearly progress (AYP). As a result, the school has been involved in several extensive reform efforts to improve students' academic achievement in reading. Despite their academic struggle, the school has seen steady gains in students' reading test scores. Since the inception of this literacy initiative extensive efforts have been made to address students' academic achievement in reading. As a result of their participation in a school-wide literacy reform, the school has been a work in progress in building a structure of literacy rich classrooms and improving students' literacy achievements.

\section{Participants}

Since the goal of this study was to examine the integration of literacy instruction in the major disciplines, a purposeful sampling approach (Patton, 2001) was used to identify teachers who emphasized literacy instruction in discipline specific classes. Teacher selection was based on suggestions from the school's literacy coaches of the ninth and tenth grade teachers who participated in the school's professional development and who worked with an instructional coach. The teachers who volunteered to participate in the study represented the four major disciplines of math, science, history and English.

Table 1: Research Participants

\begin{tabular}{llll}
\hline Teacher & $\begin{array}{l}\text { Years of } \\
\text { Experience }\end{array}$ & \multicolumn{1}{c}{ Degree } & $\begin{array}{l}\text { Grade/Subject } \\
\text { Taught }\end{array}$ \\
\hline 1 & 3 & Bachelor + & $9^{\text {th }}-$ Algebra \\
\hline 2 & 2 & Bachelor +24 & $10^{\text {th }}$ - Geometry \\
\hline 3 & 4 & Bachelor + & $10^{\text {th }}-$ World History \\
\hline
\end{tabular}




\begin{tabular}{llll}
4 & 5 & Bachelor +24 & $9^{\text {th }}-$ History \\
\hline 5 & 6 & Bachelor + & $9^{\text {th }}-$ General Science \\
\hline 6 & 2 & Bachelor + & $9^{\text {th }}-$ General Science \\
\hline 7 & 7 & Masters & $9^{\text {th }}-$ English \\
\hline 8 & 16 & Masters & $9^{\text {th }}-$ English \\
\hline
\end{tabular}

\section{Methodology}

This study sought to examine the knowledge and beliefs teachers held about literacy instruction in the above listed disciplines and to understand how these factors influenced their instructional decision-making. A case study method was used to gain an in-depth understanding of one high school's attempt to create a culture of literacy and implement a school wide literacy program. This methodology allows for intensive, holistic and meaningful description and analysis of the instructional routines and processes of teachers within the reallife context of their work (Merriam, 2002; Yin, 2003). Case studies are a valuable tool that allows for collection of evidence from multiple sources. Analysis of these multiple data sources was deemed necessary to understand how teachers' beliefs and literacy knowledge influence instructional practice.

\section{Data Collection and Data Analysis}

To gain an understanding of the relationship among teacher beliefs, knowledge, instructional routines, and contextual factors, two methods of data collection were used: semi-structured interviews and classroom observations.

\section{Interviews}

Marshall and Rossman (2006) state that the primary goal of the interview was to immerse in the natural setting and to "capture the deep meaning of experience in the participants' own words" (p.55). Interviews were conducted with eight teachers to ascertain their knowledge and beliefs about discipline specific literacy instruction. Research asserts that teachers' knowledge and beliefs about literacy instruction within the disciplines influences their instructional decisions and practices (Hall, 2005; Anders et al., 2000; Guskey, 2000; Moje, 1996).

A semi-structured interview protocol guided the discussion with the teachers. Teacher interviews took approximately 45 minutes. The focus was threefold: (a) professional background information, (b) lesson planning, and (c) instructional implementation. The background section of the teachers' interview protocol was designed to gain information about the teachers' professional background including years of teaching experience and educational background. The lesson planning section was the primary focus of the teachers' interview protocol. During the interview, each teacher was asked to explain, in detail, the following: (a) his/her instructional practices for the observed lessons (b) materials to be used, (c) how s/he planned to facilitate student learning, and (d) what literacy 
strategies s/he would ask students to use in order to learn content information. Interviews were taped and transcribed verbatim in order to gain an accurate depiction and deep meaning of experiences in the participants' own words. Data from the interviews were analyzed and interpreted based on the participants' responses and the researcher's understanding of what was said. To create meaning from the participants' experiences, the data collected from the interviews were analyzed as they were collected and organized into categories that illustrated the participants' experiences. The study's purpose, the knowledge and orientation of the research, and the meaning of participants' experiences were used to create categories (Schram, 2003; Dana \& Silva, 2003).

The data analysis was descriptive in nature and advances to developing categories from recurring themes found within the data. Understanding data collected from interviews consisted of: (a) reading each transcript line by line, (b) studying and identifying key phrases that related directly to the beliefs, knowledge, and integration of discipline specific literacy instruction, (c) analyzing the meaning of each significant statement or phrase, and (d) organizing key phrases into categories of major themes. Categories were systematically created to answer the study's research questions. The data that were relevant to answering the research questions were placed into specific categories and subcategories. The obtained data were placed into one or more categories to accurately reflect how the participants' understood and made meaning of their experience. This type of qualitative inquiry allowed the researcher to identify major themes and patterns that emerged from the interviews. The meaning and insights from the interview data were used to create a complete understanding of the participants' experiences and contributed to the findings of the study.

\section{Observations}

For Marshall and Rossman (2006) questionnaires are limited in that they lack the ability to reveal and understand deeply held beliefs and values and they offer "little value for examining complex social relationships or intricate patterns of interaction" (p.126). Teacher observations were conducted after interviews. They were utilized to validate the accuracy of the participants' responses and to gain a deeper understanding of complex interactions in natural social settings (Marshall \& Rossman, 2006). Observations were also used to explore and describe the instructional repertoire of content area teachers as well as understand the culture of literacy and various literacy expectations in discipline specific classrooms. In addition, observations explored how teachers enact their beliefs and knowledge about literacy instruction in their discipline. In order to systematically track teachers' instructional practices, protocols were developed to guide the observations. The observation protocol focused on teachers' instructional routines and practices in secondary classrooms from across the major disciplines (science, math, social studies, and English) and accounted for the number of literacy-focused activities in each classroom. The observation protocol consisted of five categories including: (a) literacy focus (b) facilitation of learning (c) student grouping methods (d) materials used and (e) literacy strategies used by students. 
The literacy activities that the teacher asked students to perform were coded (e.g. such as reading, writing, listening, or speaking). Facilitation of learning described the teachers' instructional practices and the method teachers employed to present content information. Examples of teachers' facilitation of learning included lecture, direct explanation, or guided practice. Grouping methods and materials noted how the teacher employed differentiated instructional routines and resources to support student learning. Literacy strategies included strategies that teachers used to guide students' literacy activities. Teacher observations revealed the ways in which teachers used literacy practices to connect content to students' prior knowledge, engage students in learning content information, and develop students' literacy skills. The observation protocol was used to observe each teacher for two consecutive lessons; each lesson took 40 minutes. Coding was done for every category, every ten minutes, for a total of four, ten -minute segments. The observer would observe and then note for each of the categories, which of the specific activities or behaviors were seen. Therefore, during a ten- minute segment, a teacher may have had students read and also write; therefore, both would be coded as occurring during that particular segment. The following table is an example of how the literacy focus section of the observation protocol from one teacher may be coded.

Table 2: Sample Observation Protocol

Segment of Time

$\mathrm{N}=(\%$ of time spent on activity $)$

Observe 1

Observe 2

\begin{tabular}{|llll} 
Literacy Focus & & & \\
& Reading & $3 / 4(75 \%)$ & $4 / 4(100 \%)$ \\
& Writing & $4 / 4(100 \%)$ & $4 / 4(100 \%)$ \\
Facilitation of Learning & & \\
& Direct Explanation & $4 / 4(100 \%)$ & $2 / 4(50 \%)$ \\
& Discussion & $1 / 4(25 \%)$ & $3 / 4(75 \%)$ \\
& Guided Practice & $1 / 4(25 \%)$ & $1 / 4(25 \%$ \\
Strategies Used & & & \\
& Key term & $2 / 4(50 \%)$ & $2 / 4(50 \%)$ \\
& Read/Think Aloud & $1 / 4(25 \%)$ & $1 / 4(25 \%)$ \\
& Think/Pair Share & $1 / 4(25 \%)$ & $1 / 4(25 \%)$ \\
Student Grouping & & \\
& & $4 / 4(100 \%)$ & $3 / 4(75 \%)$ \\
& Whole Group & $1 / 4(25 \%)$ & $1 / 4(25 \%)$ \\
Materials Used & Pairs & $4 / 4(100 \%)$ & $3 / 4(75 \%)$ \\
& Student Notebook & $4 / 4(100 \%)$ & $3 / 4(75 \%)$ \\
& Handout & $4 / 4(100 \%)$ & $1 / 4(25 \%)$
\end{tabular}




\section{Findings across Teachers}

The purpose of this study was to examine teachers' knowledge and beliefs about discipline specific literacy instruction. Researching the beliefs, knowledge, and practices of discipline specific teachers was critical in understanding how their experiences shaped their instructional practices. Teachers in this study have been exposed to various professional development activities that focused on integrating discipline specific literacy instruction; they were expected to infuse literacy into the discipline they taught. In addition, teachers had an established routine or set of specific practices that emphasized literacy in their classrooms.

Classroom observations support the notion that the school wide goal is to promote discipline specific literacy instruction. Interviewing teachers offered insight into how teachers develop their beliefs and knowledge of literacy instruction as well as which factors influence their instructional practices. Throughout the current study, teachers discussed important information about their instructional experiences. Common characteristics that teachers appeared to share were identified. The latter included teacher practice, teacher beliefs, and teacher learning. These collective, core components of teachers' experiences formed the findings of this study.

\section{Teacher Practice}

Throughout the study, teachers explicitly taught students how to use literacy strategies to improve discipline specific learning. To help students develop an in-depth understanding of what they were learning, teachers explicitly taught students how to use literacy strategies to improve discipline specific learning. Although there were numerous strategies to choose from, teachers used a core set of strategies, such as key term search, read-think alouds, critical reading, and pair/shares.

The major difference with the use of these strategies occurred when teachers implemented the strategies to support discipline specific literacy practices. Each teacher who participated in this study expressed specific beliefs about what it means to be literate in a particular discipline and which literacy practices are the most important for that specific discipline. For example, English teachers commonly used read-think alouds as a means for students to discuss their knowledge of the text, to analyze characters' motives, and to make connections between various themes within the text. Science teachers tended to use readthink alouds to build prior knowledge, to learn and review specialized vocabulary, and to engage in scientific inquiry and make scientific predictions. For teachers, their decision about how to use specific literacy strategies were based on their beliefs about what it means to be literate in the discipline they taught. In addition to sharing a core set of strategies, teachers employed similar instructional practices to facilitate student learning including discussion, questioning, and guided practice. Teachers' facilitation of learning also reflected their professional learning. Classroom instruction aligned with the researchbased literacy strategy instruction that was infused into classrooms to promote student engagement, problem solving, and critical thinking. Figure 1 represents how teachers developed literacy rich classrooms across the disciplines. By 
creating literacy classrooms across the disciplines, students were consistently exposed to a variety of instructional practices that support their literacy learning throughout the day. As a result, students not only learn content, but they used the habits and skills of a good reader such as making predictions, asking questions, summarizing, monitoring understanding, and relating new information to previously learned content (Monte-Sano \& De La Paz, 2014; Lee, 2007, Allington, 2005).

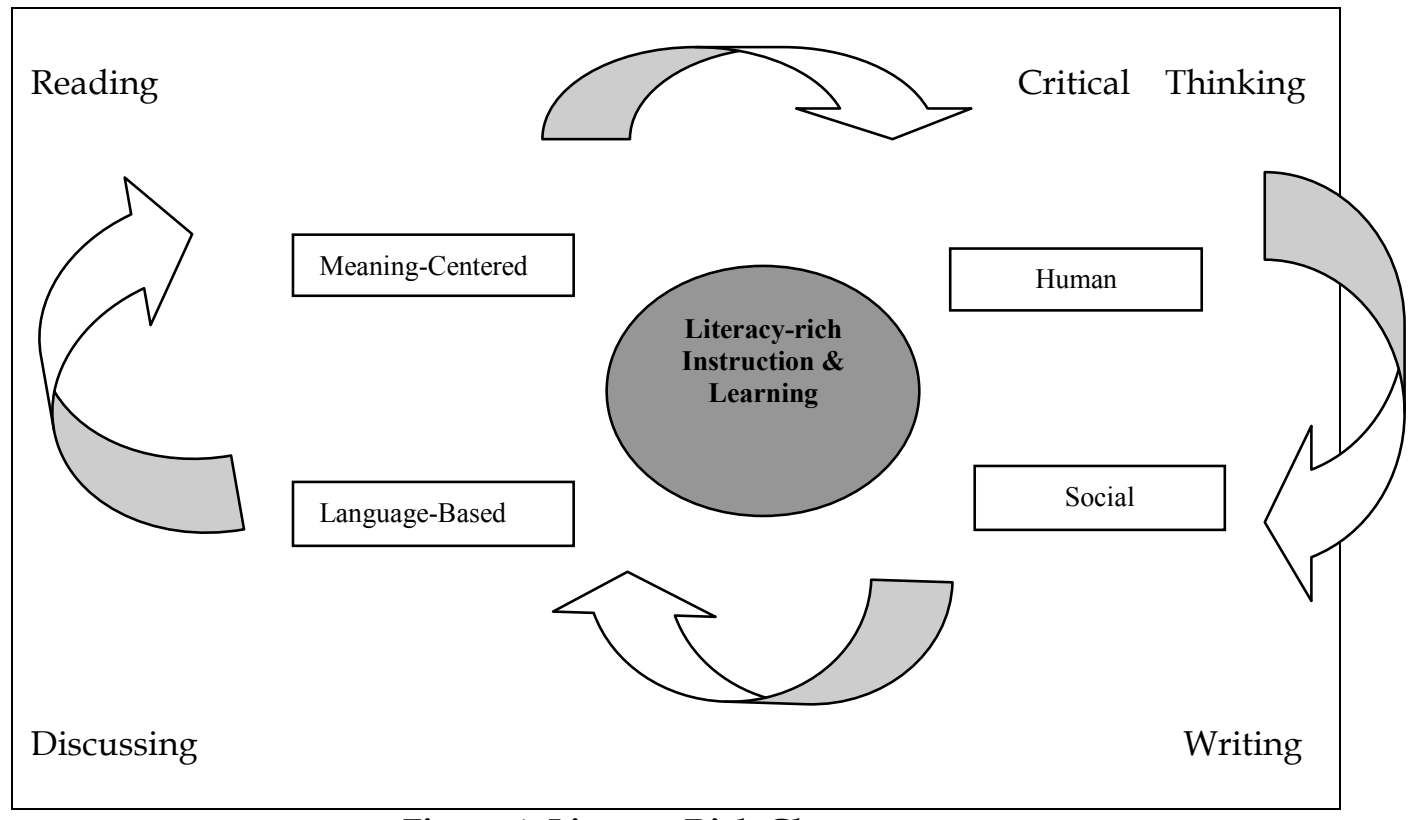

Figure 1: Literacy Rich Classrooms

All teachers adhered to the framework and their instruction provided evidence of literacy-rich classrooms that emphasized the importance of having students read, write, think, and discuss as way to actively engage students and deepen their learning. This type of instruction allowed students to develop routines that were necessary to learn pertinent literacy practices specific to each discipline (Lee \& Spratley, 2010).

One history teacher believed that teaching literacy aided students in learning the course content. She explained that critical thinking is the most imperative of literacy for students to learn. She stated:

Students need to have solid critical thinking skills. They need to think critically to understand basic concepts, learn vocabulary, and then make the connections to how all the information relates to one another. I know my students really struggle with critical thinking. They will get the basic facts, but it stops there. They have difficulties making connections between current and World History or even understanding how one event affected another event in a different time period or different part of the world.

This teacher believed that students needed to develop critical thinking skills in order to be successful in her class. Through oral readings and class discussions, she implemented discipline specific literacy instruction by helping students make critical connections between important events and historical documents 
throughout history. By making critical connections, students were able to think critically and understand how different sources of information relate to one another.

Teachers taught students instructional routines using core literacy strategies such read/think alouds, key term, pair/shares, and critical reading strategies. By building instructional routines through core strategy instruction, teachers were able to provide a classroom structure in which students internalized classroom routines and understood the how and why of using various strategies within the discipline. This type of learning is the result of teachers creating a literacy rich classroom structure that promotes an array of literacy competencies including, but not limited to reading a range of challenging material and making meaning from it, thinking critically about content information, and engaging in discipline specific inquiry. Through literacy rich classrooms and instruction, students build knowledge of content and how that content relates to other disciplines, themselves, and the world in which they live.

\section{Teacher Beliefs}

Critical to their instructional decisions are the beliefs teachers hold about what students should and how they should learn (Fang, 2014; Pourdavood \& Lui, 2017). Secondary teachers' beliefs about literacy instruction are situated within their knowledge about teaching and learning in a specific discipline. Depending on teachers' beliefs, discipline specific literacy instruction may or may not be a relevant component of secondary classrooms. The teachers in this study held similar beliefs about discipline specific literacy instruction in that they assumed responsibility for the literacy skills of their students. Teacher beliefs about literacy instruction were evident in their instructional planning and practices. Teachers expressed the need to develop students' literacy skills in order to learn content specific information. To do so, teachers emphasized discipline specific literacy practices and strategies equally as much as they emphasized course content. Teachers believed that improving students' literacy skills would ultimately improve students' content knowledge. Teachers were able to enhance content learning by teaching students how to use literacy strategies to read complex material, think critically and understand discipline specific information.

Research asserts that secondary teachers often struggle with finding time to devote to literacy and content instruction. Traditionally, secondary teachers would favor teaching content over literacy in order to meet the demands of a standards based curriculum and standardized testing by which students are assessed. However, teachers in this study believed that students would benefit more and better learn discipline specific information when they have opportunities to develop advanced literacy skills. Although they held similar beliefs about the importance of discipline specific literacy instruction, teachers' definitions of literacy were different and were situated within the discipline they taught. Each teacher was aware of the literacy skills and practices that were pertinent in their field. Likewise, teachers believed that students should learn how to orient themselves as if they were members of that discipline. Teachers encouraged students to read, think, and write as if they were mathematicians, 
scientists, or historians. For example, one math teacher defined math literacy as the ability to read numbers, symbols, and graphs and to communicate that into words. She enacted her belief of math literacy by providing students with multiple opportunities to compute, solve, and write explanations for mathematical problems. Another math teacher also believed that students should be able to explain how they solved mathematical problems. His belief about literacy instruction was evident in his instructional practice because he provided students with numerous opportunities to write and discuss their answers.

An English teacher defined literacy as the ability to understand what one reads and to apply that knowledge to other reading material and life experiences. As a result, he engaged students in activities that allowed students to question and discuss the ideas expressed in complex texts. The other English teacher believed that students should be able to read and analyze various works of literature. In order to do so, she believed that students had to make critical connections within and between texts. She enacted her beliefs about literacy by providing students with opportunities to read critically and discuss what they read.

In their classrooms, teachers implemented literacy practices that supported their beliefs and that were specific to their discipline. However, the origins of their beliefs were different. Teacher beliefs were also influenced by their educational background and professional experiences. Many of the novice teachers easily adapted to the school's literacy reform since their undergraduate education emphasized literacy instruction in the disciplines.

\section{Teacher learning}

Changing teachers' beliefs and instructional practices require a concerted effort that focuses on providing teachers with hands-on opportunities to learn the theoretical rationale of research based literacy strategies and to apply the most effective instructional practices (Correnti, 2007; Gomez \& Gomez, 2007;). Effective professional development allows teachers to learn content as well as interact and communicate with one another about what they learned and how it applies to their individual classroom. As part of the literacy based school reform, intensive professional development sessions were designed as a lever for changing teacher practice and for supporting instructional improvement.

To improve instruction, the school instituted school-wide professional development in order to increase teachers' knowledge and practice of discipline specific literacy learning and instruction. Professional learning communities specific to the discipline they taught were created to address those literacy practices most pertinent to each discipline. Content specific professional development focused on providing teachers with consistent and ongoing opportunities to extend their knowledge of literacy instruction in addition to their content and pedagogical knowledge (Correnti, 2007; McLaughlin \& Talbert, 2001). Since professional development activities were divided by subject matter, each discipline formed a professional learning community that was led by an instructional coach who possessed content expertise. Teachers were required to 
attend content specific professional development, which occurred once or twice a month.

\begin{tabular}{|c|c|c|}
\hline Month & Topic & Literacy Focus \\
\hline \multirow[t]{2}{*}{ September } & \multirow[t]{2}{*}{ Instructional Expectations } & Literacy Strategy \\
\hline & & Instruction \\
\hline October & Learning Targets & Literacy Standards \\
\hline November & Rubrics & Writing Assessments \\
\hline December & Formative Assessments & Strategy Instruction \\
\hline January & Data Driven Instruction & Reading 4Sights \\
\hline February & Differentiated Instruction & Strategy Instruction \\
\hline March & State Test Preparation & Writing Instruction \\
\hline
\end{tabular}

Teachers credited their knowledge and practice of discipline specific literacy instruction to their professional learning experiences that occurred throughout the year. The professional learning of teachers was evident in their instructional lesson planning and practices. Throughout classroom observations, teachers consistently used instructional practices that allowed students to think critically and use core set of literacy strategies.

Teachers were developing a deep understanding of what it means to engage students in discipline specific literacy practices that allowed students to function as junior members of the field. During professional learning activities, teachers collaborated with instructional coaches and other content teachers in order to learn how to create literacy rich environments, to build a curriculum that promotes discipline specific literacy practices, and to maintain student-centered classrooms that support active engagement. Teachers regularly encountered opportunities to learn how to use specific literacy strategies in their discipline through demonstration lessons initially led by the instructional coach. As time progressed, teachers offered examples of their own literacy based classroom instruction.

Teachers were able to discuss, explore, and examine effective methods of integrating literacy instruction along with content learning. This type of learning created an environment for teachers that allowed them to apply what they learned through professional development and to transform their instructional practices. The professional learning communities functioned as a support system to teachers that would play a critical role in sustaining instructional changes. Although all teachers participated in professional development activities, there were variations in their understanding and implementation of disciplinary literacy instruction. Teachers who were involved in professional learning activities for more than a year seemed to have developed a more thorough understanding of discipline specific literacy instruction and the school-wide literacy. Nonetheless, all teachers were in the process of developing disciplinary specific literacy knowledge and effective instructional practices. Teacher learning was a critical component of the school's literacy reform. In order for student achievement to improve, teachers' 
instructional practices had to improve. Since their involvement in the literacy reform, and more specifically their participation in extensive professional development, teachers have gained a critical consciousness into their instructional role of meeting the literacy needs of students within the disciplines. Teachers gained insights as to the need to address and include literacy instruction in their classrooms. As part of their critical consciousness, teachers were becoming more aware of their literacy knowledge and instructional practices; thus, they learned how to adapt their instructional practices. While working closely with the schools administration and literacy coaches, teachers' literacy instruction within the disciplines was a work in progress with the goal of increasing student achievement by improving instruction. Teachers were beginning the process of becoming experts in discipline specific literacy instruction.

\section{Discussion}

A great deal of focus in educational research has revolved around improving students' academic performance and teacher instruction, particularly within the field of literacy. With performance-based accountability driving educational policies and reform, schools have functioned under a canopy of changes in academic standards, curriculum, pedagogy, and school organization. Research asserts that critical changes in teacher instructional practices can produce improvement in student achievements (Moje, 2015; Sherer et al., 2009; Elmore, 2004; Leithwood et al., 2004). To improve student academic performance by improving teacher instruction, secondary schools must be able to specifically identify the practices that will lead to sustained instructional changes. If students are to acquire literacy skills that allow them to learn academic and occupational related information, to think critically across disciplines, and to function and communicate within multiple, diverse communities, then schools must align their agenda to foster the kind of instruction and learning that develops competent citizens for a rich multi-literate society.

Improving literacy achievement in secondary schools is the result of an integrated and coherent effort that explicitly articulates how students think, act, and learn as a result of completing the school's program of instruction (Conley, 2008). Therefore, secondary schools must focus their literacy reform efforts on developing academic programs that connect with the expected level of knowledge and the needed skills to succeed in college and the workforce. The ultimate goal of discipline specific literacy is to prepare students for a changing society in which reading to learn a range of information in varied contexts will become critical to one's success. The successful integration of disciplinary literacy instruction at the secondary level involves collaborative efforts among teachers, administrators, and other literacy leaders within a school that provides professional learning opportunities that lead to in-depth and sustained changes in instructional practices. Hence, continuous professional development is paramount. In order for teachers to transform their thinking and learn how to integrate literacy instruction in their discipline, schools must develop an infrastructure that allows teachers to engage in professional learning opportunities that aid them in developing and incorporating effective literacy 
practices. Professional development opportunities are ultimately designed to improve student learning and academic achievement by enhancing teachers' attitudes, knowledge, and instructional skills (Rainey, 2017; Guskey, 2000).

Within a school wide literacy reform at the secondary level, such professional development evolves from extended opportunities to learn over a period of time. Anders et al. (2000) suggest that effective professional development includes an extensive commitment to involving teachers in opportunities to learn through ongoing support, deliberation, and collaboration. While teachers need to participate in activities that allow them to critically reflect on their instructional practices, they also need time to develop the necessary subject matter knowledge. In addition, it is important to emphasize that the focus of school based professional development should primarily focus on the content teachers teach and should align with their actual work in the classroom so that teachers develop a deep content and pedagogical knowledge as well as understand how students learn the content (Desimone et al., 2002).

Research widely supports the notion that professional development must expose teachers to sustained, ongoing, job-embedded professional learning opportunities that are supported by effective modeling and coaching that specifically address the needs of the teachers and the school (Bean, 2004; Guskey, 2000; Darling-Hammond \& McLaughin, 1994). This process of change requires the influence of an instructional leader or leaders who build teachers' capacity by providing the instructional and structural support. Support mechanism like common planning time, block scheduling, or peer observations would allow sufficient time for teachers to engage in opportunities to learn and to increase their content knowledge that would result in literacy instruction throughout the day and across the disciplines. For the implementation of disciplinary literacy instruction to succeed, there must be a strong foundation of strategic leadership that organizes and guides the systematic practice of disciplinary literacy instruction and builds the capacity to sustain instructional changes (McConachie \& Apodaca, 2012).

\section{Recommendations and Implications for Future Research}

Implementing a coherent literacy initiative at the secondary level is a complex and at times, an elusive process that at its core involves a central focus of improving student learning and achievement by improving the instructional base of a school's organization. School improvement, therefore, occurs as a result of building and enhancing the knowledge and skills of multiple players and involves intertwined and layered relationships among district personnel, school leadership, teachers, and students. All stakeholders across the educational spectrum must be involved in the effort to building the capacity to systematically incorporate discipline specific literacy instruction into the school's curricular and instructional efforts. Replicating this study in other high schools that have similar demographics and could provide further insight about the benefits and challenges of the systematic implementation of literacy instruction across the disciplines. Examining other literacy initiatives at the secondary level could offer multiple perspectives as to how to successfully implement a school 
wide literacy reform. Comparing the results from schools involved in various school-wide literacy initiatives could contribute to the body of research on effective secondary literacy instruction. A similar study should be conducted with schools that have a smaller population and different demographics to compare the similarities, differences, and impact of discipline specific literacy instruction.

Developing teachers' knowledge and instructional practices are important components of disciplinary literacy instruction at the secondary level. The instructional leaders of a school must organize a school so that everyone develops an understanding and implements the practice of discipline specific literacy instruction, engages in discipline specific professional development, and receives the appropriate supports to sustain effective literacy instruction. Through strategic leadership, teachers and literacy leaders must work towards the same goal of improving students' literacy skills. Several dimensions of a successful literacy initiative at the secondary level should include a) well defined literacy goals and objectives; (b) school-wide nature of the initiative; (c) support of instructional leadership for teachers and their professional learning, and (d) the use of a variety of literacy strategies that emphasize the meaning centered, social, language based, and human aspects of literacy learning. As a result, a school's literacy reform is dependent on the rich interactions among teachers, instructional coaches, and the school's principal that help to create and implement a school improvement plan to advance the knowledge base, skill, and instructional routines of teachers.

Understanding teachers' beliefs and knowledge of discipline specific literacy instruction are paramount to their instructional decision-making and ultimately their instructional practice. Analyzing preparation programs and certification requirements are necessary in preparing teachers to infuse literacy across the curriculum. While the ultimate goal of discipline specific literacy instruction is student academic growth, the major goals of this study focused on what teachers know and do to integrate discipline specific literacy instruction. Thus, students' perspectives and assessment data were not a part of this study. Including students' viewpoints could offer insight as to how they develop habits of thinking and practice across the disciplines in addition to how teachers support students' literacy learning. Analyzing student assessment data could provide critical information about the effects of teacher instruction.

\section{Conclusion}

The purpose of this study is to explore the integration of disciplinary literacy instruction as part of a comprehensive literacy program at the secondary level. This study focused on secondary teachers' knowledge, beliefs, and instructional practices relating to disciplinary literacy throughout one school's effort to create and sustain a comprehensive, school-wide literacy program. 
This study seeks to contribute to the understanding of how a school's organization functions or fails to function as a whole to improve the literacy skills of adolescent learners by creating the common goal of integrating disciplinary literacy instruction at the secondary level. Teachers, adminstrators, and other literacy leaders play critical roles in developing a variety of teacher knowledge and instructional routines that enhance a coordinated school wide literacy program. In addition, this research contributes to an increased understanding among educators, administrators, and policy makers with respect to the necessary organizational and instructional support needed for improved literacy instruction and learning at the secondary level. Finally, findings provide insight for teacher education programs as to how to design and improve programs to prepare content area teachers to integrate disciplinary literacy instruction.

There is a considerable body of knowledge that addresses the pervasive problem of adolescent literacy and the literacy requirements that are necessary to meet the reading demands in the disciplines as well as in the workforce. That is, what advanced literacy skills students need to develop and what they need to know in order to lead productive and successful lives both in and out of school. Secondary schools are faced with the challenge of focusing on the collaborative process among teachers, administrators, and instructional coaches in order to expand literacy instruction to secondary grade levels and more specifically to tailor that instruction to promote college and career readiness through discipline specific literacy practices.

While much of the current research in discipline specific literacy instruction focuses solely on teacher practice or professional development for teachers, the discussion needs to expand and connect to families, communities and the nation at large. Literacy is a mechanism of power because it is fundamental to informed decision-making as well as active participation in all aspects of society. Secondary teachers have a colossal opportunity and responsibility to serve as change agents within in their schools and society at large.

\section{References}

Allington, R. (2005). What really works for struggling readers: Designing research-based programs. Boston: Allyn and Bacon. doi: 10.1086/461151.

Anders, P.I., Hoffman, J.V., Duffy, G.G. (2000). Teaching teachers to teach reading: Paradigm shifts, persistent problems, and challenges. In M.L. Kamil, P.B. Mosenthal, P.D. Pearson, \& B. Barr (Eds.), Handbook of reading research: Volume III (pp. 719-742). Mahwah, NJ: Erlbaum. doi: 10.4324/9781410605023.ch38.

Bain, R. (2000). Rounding up unusual suspects: Using research and theory to shape history instruction. In P. Stearns, P. Seixas, \& S. Wineburg (Eds.), Knowing, teaching, and learning history: National and internationals perspectives (pp. 331-353). New York: New York University Press.

Bean, T.W. (2000). Reading in the content areas: Social constructivist dimensions. In M.L. Kamil, P.B.Mosenthal, P.D. Pearson, \& B. Barr (Eds.), Handbook of reading research: 
Volume III (pp. 629-644). Mahwah, NJ: Erlbaum. doi: 10.4324/9781410605023.ch34.

Bean, R. (2004). The reading specialist. Leadership for the classroom, school, and community. New York, NY: Guilford Press.

Biancarosa, G., \& Snow, C. (2006). Reading next: A vision for action and research in middle and high school literacy: A report to the Carnegie Corporation of New York (2 ${ }^{\text {nd }}$ Ed.). Washington, DC: Alliance for Excellent Education.

Bintz, T. (1997). Exploring reading nightmares of middle and secondary school teachers. Journal of Adolescent \& Adult, 41(1), 3-29.

Bransford, J.B., Brown, A.L., Cocking, R. (2000). How people learn: Brain, mind, experience, and school.National Academy Press: Washington, D.C. doi: $10.17226 / 9853$.

Buchman, M. (1987). Teaching knowledge: The lights that teachers live by. Oxford Review of Education, 13, 151-164. https://education.msu.edu/NCRTL/PDFs/NCRTL/IssuePapers/ip871.pdf.

Conley, D.T. (2008). College knowledge: What it really takes for students to succeed and what we can do to get them ready. Hoboken, NJ: Wiley.

Castek, J. and Beach, R. (2013). Using apps to support disciplinary literacy and science learning. Journal of Adolescent $\mathcal{E}$ Adult Literacy, 56(7), 554-564. doi 10.1002/JAAL.180.

Correnti, R. (2007). An empirical investigation of professional development effects on literacy instruction using daily logs. Education Evaluation and Policy Analysis, 29, 239-261. journals.sagepub.com/doi/full/10.3102/0162373707309074.

Dana, N. F., \& Silva, D. Y. (2003). The reflective educator's guide to classroom research: Learning to teach and teaching to learn through practitioner inquiry. Thousand oaks, CA: Corwin Press, INC.

Darling-Hammond, L., \& McLaughlin, M.W. (1994). Policies that support professional development in an error of reform. Phi Delta Kappan, 76, 597-604. doi/abs/10.1177/003172171109200622.

Desimone, L.M., Porter, A.C., \& Birman, B.F. (2002). Effects of Professional development on teachers' instruction: Results from a three-year longitudinal study. Educational Evaluation and Policy Analysis, 24(2), 81-112. http://journals.sagepub.com/doi/pdf/10.3102/01623737024002081

Donahue, D.M. (2000). Experimenting with texts: New science teachers' experience and practices as readers and teachers of reading. Journal of Adolescent $\mathcal{E}$ Adult Literacy, 43(8), 728-739. http://www.jstor.org/stable/40014698.

Elmore, R. (2004). School reform from the inside out: Policy, practice, and performance. Cambridge, Massachusetts: Harvard Educational Press.

Fang, Z. (2014). Preparing content area teachers for disciplinary literacy instruction. Journal of Adolescent and Adult Literacy , (57(6), 444-448. Doi 10.1002/jaal.269.

Goldman, S.R., Brit, M., Brown, W., Cribb, G., George, G., \& Greenleaf, C. (2016). Disciplinary literacies and learning to read for understanding: A conceptual framework for disciplinary literacy. Educational Psychologist,51(2), 219-246. https://doi.org/10.1080/00461520.2016.1168741.

Gomez, L. \& Gomez, K. (2007). Reading for learning: Literacy supports for $21^{\text {st_century }}$ Work. Phi Delta Kappa International, 89 (3), 224-228 
Graue, M. E., \& Walsh, D. J. (1998). Studying children in context: Theories, methods, and ethics. Thousand Oaks, CA: Sage.

Guskey, T. (2000). Evaluating Professional development. Thousand Oaks, CA: Corwin Press.

Hall, L.A. (2005). Teachers and content area reading: Attitudes, beliefs and change. Teaching and Teacher Education, 21,403-414. https://doi.org/10.1016/j.tate.2005.01.009

Heller, R., \& Greenleaf, C. (2007). Literacy instruction in the content areas: Getting to the core of middle and high school improvement. Alliance for Excellent Education: Washington, D.C. http://www.all4ed.org

Herber, H.L. (1970). Teaching reading in the content areas. Englewood Cliffs, NJ: Prentice Hall.

Knapp, M. S., Copland, M. A., \& Talbert, J. E. (2003). Leading for learning: Reflective tools for and district leaders. Center for the Study of Teaching and Policy. http://www.ctpweb.org.

Lee, C.D. (2007). Culture, literacy, and learning: Taking Bloom in the midst of the whirlwind. NY: Teachers College Press

Lee, C. D., \& Spratley, A. (2010). Reading in the disciplines: The challenges of adolescent literacy. New York, New York: Carnegie Corporation of New York. https:// www.carnegie.org/media/filer_public/88/05/880559fd-afb1-49adaf0ee10c8a94d366/ccny_report_2010_tta_lee.pdf

Leithwood, K. Louis, K.S., Anderson, S., \& Wahlstorm, K. (2004). How leadership influences student learning.

Center for Applied Research and Educational Improvement. Retrieved December 10, 2008 from http://www.wallacefoundation.org/knowledgecenter/Documents/How-Leadership-Influences-Student-Learning.pdf

Marshall, C. \& Rossman, G.B. (2006). Designing qualitative research. Thousand Oaks, CA: Sage.

McLaughin, M. \& Talbert, J. (2001). Professional communities and the work of high school teaching. Chicago: University of Chicago press.

Merriam, S. B. (2002). Qualitative research in practice: Examples for discussion and analysis. San Francisco: Jossey-Bass.

Moje, E.B. (1996). "I teach students, not subjects": Teacher-student relationships as contexts for secondary literacy. Reading Research Quarterly, 31,173-195. doi/10.1598/RRQ.31.2.4/pdf.

Moje, E.B. (2008). Foregrounding the disciplines in secondary literacy teaching and learning: A call for change. Journal of Adolescent \& Adult Literacy, 52(2), 96-107. doi: 10.1598/JAAL.52.2.1.

Moje, E.B. (2015). Doing and teaching disciplinary literacy with adolescent learners: A social and cultural enterprise. Harvard Educational Review, 85(2), 254-278. https://doi.org/10.17763/0017-8055.85.2.254

McConachi, S.M. \& Apodaca, R.E. (2010). Embedding disciplinary literacy: Leadership and professional learning. In S.M. McConachie \& A.R. Petrosky (Eds.), Content matters (pp.163-196). Jossey-Bass. doi: 10.1002/9781118269466.ch7.

Monte-Sano, C., De La Paz, S. (2014). Implementing a disciplinary-literacy curriculum for US history: Learning from expert middle school teachers in diverse classrooms. Journal of Curriculum Studies, 46(4), 540-575. http://doi.org/10.1080/00220272.2014.904444. 
Moore, D., Readence, J.E., \& Rickelman, R.J. (1983). An historical exploration of content area reading instruction. Reading Research Quarterly, 419-438. doi: $10.2307 / 747377$.

National Reading Panel. (2000). Teaching children to read: An evidence-based assessment of the scientific research literature on reading and its implications for reading instruction. Retrieved January 12, from https://www1.nichd.nih.gov/publications/pubs/nrp/Documents/report.pdf.

O'Brien, D., Stewart, R., Moje, E. (1995). Why content literacy is difficult to infuse into secondary school: Complexities of curriculum, pedagogy, and school culture. Reading Research Quarterly, 30,442-462. doi: 10.2307/747625.

Pajares, M. F. (1992). Teachers' beliefs and educational research: Cleaning up a messy construct. Review of Educational Research, 62(3), 307-332.

Patton, M. Q. (2001). Qualitative evaluation and research methods (2nd ed). Newbury Park, CA: Sage. Pourdavood, R.G., \& Lui, Xiongyi. (2017). Pre-service Elementary teachers' experiences, expectations, beliefs, and attitudes toward mathematics teaching and learning. International Journal of Learning, Teaching and Educational Research, 16(11), 1-27. https://doi.org/10.26803/ijlter.16.11.1

Rainey, E.C. (2017). Disciplinary literacy in English language arts: Exploring the social and problem-based nature of literary reading and reasoning. Reading Research Quarterly, 52(1), 53-72. DOI 10.1002/rrq.154

Schram, T. (2003). Conceptualizing qualitative inquiry: Mind work for fieldwork in education and the social sciences. Columbus, $\mathrm{OH}$ : Merrill-Prentice Hall.

Shanahan, T., \& Shanahan, C. (2012). Teaching disciplinary literacy to adolescents: Rethinking content-area literacy. Harvard Educational Review: 78(1), 40-59. doi: 10.17763/haer.78.1.v62444321p602101.

Shearer, J.Z., Gomez, K., Herman, P., Gomez, L., White, J., Williams, A. (2009). Literacy infusion in a high school environmental science curriculum. In K. Bruna \& K. Gomez (Eds.), The work of language in multicultural classrooms (pp.93-114). New York: Routledge.

Shulman, L. (1987). Knowledge and teaching: Foundations of the new reform. Harvard Educational Review, $57(1), \quad 1-23$. https://doi.org/10.17763/haer.57.1.j463w79r56455411.

Torgesen, J., Houston, D., \& Rissman, L. (2007). Improving literacy instruction in middle and high schools: A guide for principals. Portsmouth, NH: RMC Research Corporation, Center on Instruction. http://www.centeroninstruction.org/files/Principal s Guide Secondary.pdf.

Yin, R. K. (2003). Case study research: Design and methods. Thousand Oaks, CA: Sage. 